\title{
A retrospective comparative analysis of two different techniques of small bowel diversion in Ileal perforation cases: a single centre experience
}

\author{
Suryavanshi $\mathbf{P}^{1}$, Rai $\mathbf{A}^{2}$, suryavanshi $A^{3}, \operatorname{Singh} \mathbf{R}^{4}$ \\ ${ }^{1}$ Dr Parijat Suryavanshi, Assistant Professor, Department of General Surgery, KGMU, lucknow, ${ }^{2}$ Dr Anurag rai, \\ Assistant Professor, Department of General Surgery, KGMU, lucknow, ${ }^{3} \mathrm{Dr}$ Abhishek suryavanshi, enior Consultant \\ Surgeon, Akanksha Hospital, Barabanki, UP, ${ }^{4}$ Dr Rupali singh, Consultant Gynaecologist, Akanksha Hospital, \\ Barabanki, UP, India
}

Address for Correspondence: Dr Parijat suryavanshi, Email: parijatsuryavanshi@gmail.com

\begin{abstract}
Introduction: Ileal perforation is a common surgical emergency especially in Indian sub-continent due to increased incidence of enteric fever and tuberculosis- two most common causes of ileal perforation. Many different techniques had been applied for treatment of perforation like primary closure, exteriorization of perforation site or primary closure with proximal diversion stoma. Many cases are not suitable for primary closure; in such cases ileostomy is done. Ileostomy is associated with significant morbidity which adds to financial burden and decreases quality of life. Tube ileostomy has been explored as an alternative to conventional ileostomy sans its morbidity. Methods: Here we retrospectively analyzed ileal perforation cases treated with either loop ileostomy or tube ileostomy at our centre during last 3 years. Result: A total of 50 ileal perforation cases treated with ileostomy either tube ileostomy $(n=21)$ or conventional loop ileostomy ( $n$ $=29$ ) were included for study and their immediate and late post operative complications were recorded and analysed.

Conclusion: We found that tube ileostomy is a safe and effective mode of diversion and is associated with minimal stoma related morbidity like peristomal excoriation, hernia, retraction, prolapse, obstruction etc.
\end{abstract}

Keywords: Ileostomy, Enteric, Perforation, Intestinal

\section{Introduction}

A diversion ileostomy was first introduced by Turnbull and Weakley in 1966 [1]. Since then it has gained much popularity. A diversion loop ileostomy is found to be especially useful in tough operating situations like matted bowel loops, grossly unhealthy bowel or multiple perforations. Such diversions allowed patients to start oral intake early [2, 3]. An ileostomy however, has significant morbidity and significantly reduces quality of life in patients. It also causes an additional increase in the cost of healthcare which is a very important factor in developing countries where diseases that lead to ileal perforations are quite common. Ileostomies themselves carry with them complications like skin excoriation, severe electrolyte abnormalities,

Manuscript received: $30^{\text {th }}$ November 2016

Reviewed: $07^{\text {th }}$ December 2016

Author Corrected: $14^{\text {th }}$ December 2016

Accepted for Publication: 20 $0^{\text {th }}$ December 2016 retraction, prolapse, necrosis etc. They also require the patient to be subject to two surgeries, which also potentially increases the complication rate in these patients [4].

The T-tube ileostomy was first used as early as 1950's [5]. Recently however, it has been increasingly explored as an alternative to conventional ileostomy. Main obvious advantages of tube ileostomy over conventional ileostomy are avoidance of stoma related morbidities and no requirement of second surgery [6].

We have been using tube ileostomy technique in ileal perforation case in selected patients of ileal perforation since last $4-5$ years with encouraging results. We hereby present a retrospective analysis of our experience with both techniques and their comparison. 


\section{Material and Method}

Type and place of study: This study is a retrospective comparative analysis of ileal perforation cases operated at Department of General Surgery, King George's Medical University, Lucknow, with diversion ileostomy done using two different techniques, during period of 3 years.

Inclusion criteria: We analyzed the records and selected all ileal perforation cases that underwent primary closure with diversion stoma. We then segregated the selected patients into two groups based on type of stoma. One group included those cases which were diverted using classical loop ileostomy and other group included cases that underwent tube ileostomy using 14 French nasogastric tube introduced in the lumen of bowel proximal to perforation and sutured adjacent to skin incision and connected to urobag. Perforation site was primarily closed in all cases using vicryl 3-0 intermittent double layer after freshening the margins by cutting $2 \mathrm{~mm}$ of bowel margin using 11 no. surgical blade (Figure 1-4). Daily flushing the tube with $5 \mathrm{ml}$ normal saline was done twice daily to keep tube patent. Early postoperative ( $<7$ days) and late postoperative (7-28 days) complications were recorded.

Statistical methods: Results were analyzed using standard statistical methods.

\section{Exclusion criteria}

- All cases with age $<15 y r s$ and $>70 y r s$ were excluded.

- All cases with blood pressure < 90 systolic at the time of surgery were excluded.

- All cases having have history of cardiac or pulmonary co-morbidities were excluded.

- All patients with history of diabetes, or newly detected diabetes during pre-surgical workup were excluded.
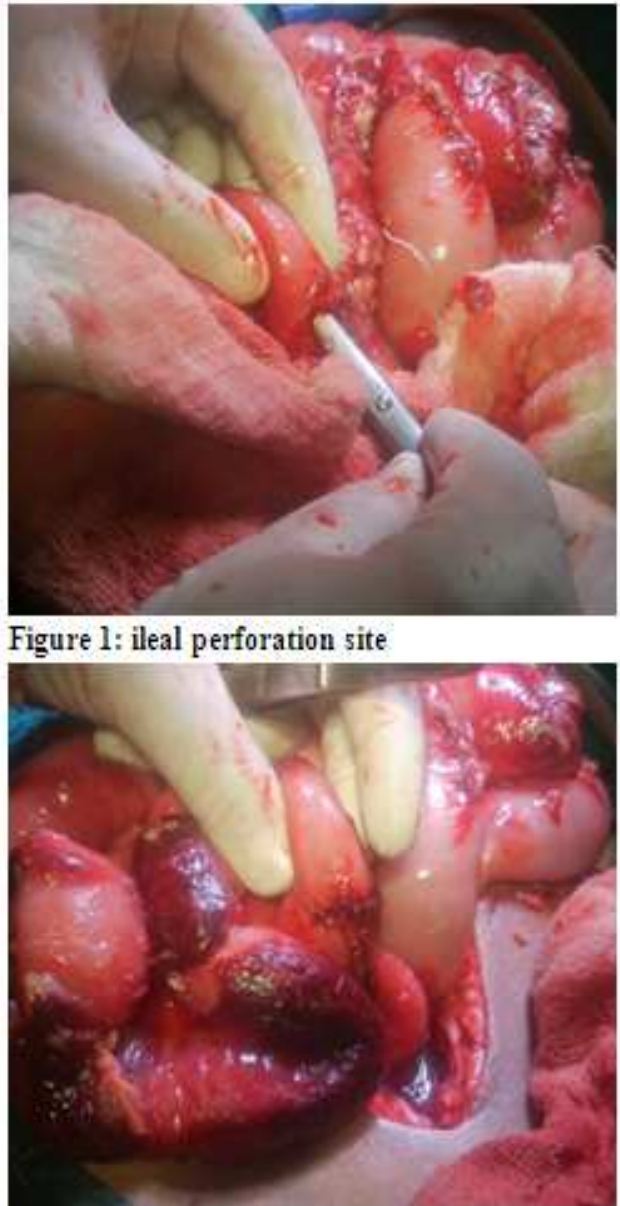

Figure 3: Primary closure completed
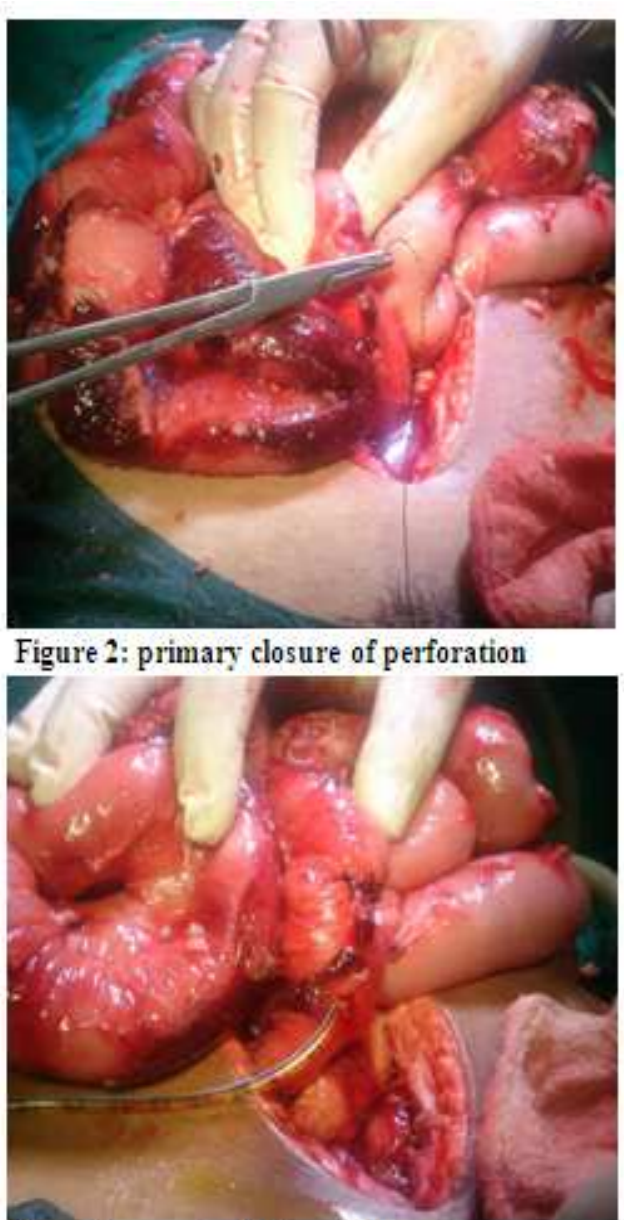

Figure 4: proximal tube placement 


\section{Results}

A total of 58 cases of ileal perforation were operated during the study period in which ileostomy by either technique was done. 8 cases were excluded from analysis as they fulfilled exclusion criteria. 50 cases were included for study and their records were analyzed. Conventional loop ileostomy was done in 29 cases $(n=29)$ and tube ileostomy was done in 21 cases $(n=21)$.

Baseline characteristics of both groups were as mentioned in table 1.

Table-1: Baseline characteristics of both groups

\begin{tabular}{|l|l|l|l|}
\hline & $\begin{array}{l}\text { Conventional } \\
\text { Ileostomy } \mathbf{n = 2 9}\end{array}$ & $\begin{array}{l}\text { Tube Ileostomy } \\
\mathbf{n = 2 1}\end{array}$ & Range \\
\hline Mean Age & 38 yrs & 28 yrs & $13-68$ yrs \\
\hline Gender & Male-20 $(68.9 \%)$ & Male-14 $(66.6 \%)$ & \\
& Female-9 $(31 \%)$ & Female-7 $(33.3 \%)$ & \\
\hline Mean Duration of Symptoms & 2 days & 1 days & $0-4$ days \\
\hline
\end{tabular}

Overall age of the patients including both groups ranged from 13 to 68 yrs (Mean age 38 yrs vs 28 yrs). Overall $68 \%$ cases were male. Main presenting complaints was Pain abdomen $(n=48 ; 96 \%)$ and obstipation $(n=45$; $90 \%)$. History of fever was present in 16 cases (32\%). Duration of complaints (from onset of symptoms to presentation in hospital) ranged from 0-4 days. Gas under diaphragm on erect $\mathrm{X}$ ray was present in 45 cases (90\%).

In conventional ileostomy group ( $\mathrm{n}=29)$, mean operative time was 1 hour and 52 minutes. In majority, loop ileostomy started to function on third day in $68.9 \%$ cases $(n=20)$. Average daily stoma output was $\sim 600$ ml. Loop ileostomy associated morbidity was present in $55.1 \%$ cases $(n=16)$ with peristomal skin excoriation being most common stoma associated complication in $37.9 \%(n=11) .2$ cases $(6.89 \%)$ needed revision surgery for stoma necrosis $(n=1)$ and retraction $(n=1)$. Wound infection was present in $13.79 \%$ cases $(n=4)$. No post operative mortality was present in this group (Table 2).

In tube ileostomy group $(\mathrm{n}=21)$, mean operating time was 1 hour and 14 minutes. Tube ileostomy started functioning in $90.4 \%$ of case on first postoperative day $(n=19)$. Average daily stoma output was $\sim 350 \mathrm{ml}$. Tube associated complication was present in $38 \%$ cases $(n=8)$ with tubal blockage being most common complication $(n=4) .3$ case had peritubal leakage $(n=3)$ and one had accidental tube extrusion $(n=1)$ with minor bile fistula which persisted for 6 days and healed spontaneously. Peristomal skin excoriation was present in $19 \%(n=4)$, which included cases with peritubal leakage and accidental tube extrusion.

One patient had anastomotic leakage $(n=1)$ with peritonitis and bile stained drain output and was re operated and loop ileostomy was done. No post operative mortality was present in this group (Table 2). Tube was removed in fourth week in all cases, with minor fistula in one case which closed spontaneously in 2 days

Table-2: Comparison between Two techniques

\begin{tabular}{|l|l|l|}
\hline & $\begin{array}{l}\text { Conventional } \\
\text { Ileostomy n=29 }\end{array}$ & $\begin{array}{l}\text { Tube ileostomy } \\
\mathbf{n = 2 1}\end{array}$ \\
\hline $\begin{array}{l}\text { Mean operative } \\
\text { Time }\end{array}$ & 112 minutes & 74 minutes \\
\hline Average day of stoma functioning & Day 3 & Day 1 \\
\hline Avg.daily output & $600 \mathrm{ml}$ & $350 \mathrm{ml}$ \\
\hline Tube associated complication & $55.1 \%$ & $38 \%$ \\
\hline Anastomotic leakage & $0 / 29$ & $1 / 21$ \\
\hline $\begin{array}{l}\text { Post operative } \\
\text { Mortality }\end{array}$ & $0 / 29$ & $0 / 21$ \\
\hline
\end{tabular}




\section{Discussion}

Ileal perforation peritonitis is a common surgical emergency in the Indian subcontinent and in tropical countries. It is reported to constitute the fifth common cause of abdominal emergencies due to high incidence of enteric fever and tuberculosis in these regions [7,8] The routine use of ileostomy in ileal perforation cases is a very common practice, especially in Indian subcontinent due to increased incidence of enteric fever as compared to west.

Fecal peritonitis is the most dreaded complication of anastomotic leak and is the main cause of postoperative mortality [9]. Ileostomy, since its practice started in 1960s, has been effective mode of fecal diversion thereby effectively prevented fecal peritonitis associated postoperative mortality [1]. But ileostomy is associated with significant morbidity, in some reports more than seventy percent cases of ileostomy are associated with morbidity adding to the duration of stay, hospital cost and having detrimental effect on quality of life with requirement of second operation for stoma closure [4].

Practice of ileostomy is quite common but it has been increasingly recognized that routine use of ileostomy is not needed in all ileal perforation and there is a subgroup of ileal perforation cases in which primary anastomosis alone is feasible. Cases of ileal perforation in which ileostomy is advocated are: when integrity of anastomosis is doubtful, multiple perforations, severely edematous, inflamed and matted bowel loops [3].

The T-tube ileostomy was first used at Texas Children's Hospital in 1959 for meconium ileus cases where surgery was done for complications or failure to evacuate meconium. They found in patients with uncomplicated meconium ileus unrelieved by contrast enema, that T-tube ileostomy is an effective and safe treatment and since then there have been several reports of tube ileostomy use in intestinal surgery. Tube ileostomy had been used in colorectal surgeries by few investigators as an alternative to conventional ileostomy [5]. Rygl et al. in their study found tube ileostomy to be an effective and safe technique in intestinal perforation in extremely low birth weight neonate [10]. Nachiappan $\mathrm{S}$ et al. in their systematic review evaluating tube ileostomy found that pooled analyses of studies comparing tube ileostomy with loop ileostomy do not show statistically significant differences in anastomotic leak rates [11].
In our study we found that tube ileostomy was an effective and safe alternative to conventional ileostomy. Ileostomy related complications were significantly less in tube ileostomy patients $(38 \%)$ as compared with conventional ileostomy group $(55.1 \%)$.

Tube ileostomy, in our study, was found to be more used in younger patients (38yrs vs $28 \mathrm{yrs}$ ) with short duration of symptoms ( 2 days vs. 1 day). Dehydration and electrolyte imbalance are an important problem with conventional ileostomy group due to high output. Reported incidence of dehydration ranges from 2.2 $20 \%$ [12]. In our study average daily stoma output was significantly low in tube ileostomy group $(\sim 350 \mathrm{ml})$ as compared to conventional ileostomy $(\sim 600 \mathrm{ml})$. Peristomal complications are quite frequent in ileostomy patients. In our study, 37.9\% of conventional ileostomy cases had peristomal skin complications as compared to $19 \%$ of patients with tube ileostomy. Peristomal complications add to the morbidity of stoma and also significantly deteriorate the quality of life due to non-applicability of stoma bag, local itching and pain, soiling of clothes and social restrictions [4]. In our study, peristomal excoriations in tube ileostomy case were minor without much effect on quality of life of patient. Out of 3 cases of peritubal leakage, 2 were successfully managed by refixing of tube to the skin with suture.

Distal anastomotic leak despite proximal diversion have been reported in literature. García-Botello et al. reported $10.24 \%$ anastomotic leak in series of 127 patients despite proximal loop ileostomy. In our study, none patients in conventional ileostomy had distal leak. In tube ileostomy group, 1 patient had distal anastomotic leak which was successfully managed by exteriorizing the anastomotic site [13].

Most notable difference between both groups was requirement of second surgery in conventional ileostomy group, with its added anesthesia and surgery related complications. In our study, in tube ileostomy group, tube was removed after 3 weeks without any significant complication.

\section{Conclusion}

Tube ileostomy is an effective and safe alternative to conventional ileostomy in majority of ileal perforation cases. It avoids significant stoma related morbidities, avoids second surgery and has good impact on quality 
of life. Further large scale randomized studies are needed to further clarify the issue whether tube ileostomy can replace conventional ileostomy in certain subgroup of patients.

Funding: Nil, Conflict of interest: None initiated, Permission from IRB: Yes

\section{References}

1. Turnbull RB, Jr., Weakley FL. Ileostomy technics and indications for surgery. Review of Surgery.1966;23(5):310-4.

2. Ahmed HN, Niaz MP, Amin MA, Khan MH, Parhar AB. Typhoid perforation still a common problem: situation in Pakistan in comparison to other countries of Low Human Development. Journal of the Pakistan Medical Association. 2006;56(5):230-2.

3. Singh KP, Singh K, Kohli JS. Choice of surgical procedure in typhoid perforation: experience in 42 cases.Journal of the Indian Medical Association. 1991;89(9):255-6.

4. Duchesne JC, Wang YZ, Weintraub SL, Boyle M, Hunt JP. Stoma complications: a multivariate analysis. Am Surg. 2002 Nov;68(11):961-6; discussion 966.

5. Mak GZ, Harberg FJ, Hiatt P, Deaton A, Calhoon R, Brandt ML. T-tube ileostomy for meconium ileus: four decades of experience. Journal of Pediatric Surgery. 2000;35(2):349-52.

6. Vijayraj Patil, Abhishek Vijayakumar, M. B. Ajitha, and Sharath Kumar L, "Comparison between Tube
Ileostomy and Loop Ileostomy as a Diversion Procedure," ISRN Surgery, vol. 2012, Article ID 547523, 5 pages, 2012. doi:10.5402/2012/547523

7. HUCKSTEP RL. Recent advances in the surgery of typhoid fever. Ann R Coll Surg Engl. 1960 Apr;26:20730.

8. Bhansali SK. Gastrointestinal perforation: a clinical study of 96 cases. J Postgrad Med. 1967;13(1):1-12.

9. Talwar S, Sharma RK, Mittal DK, Prassad P. Typhoid enteric perforation. Aust N Z J Surg.1997;67(6):351-3.

10. Rygl M, Pycha K, Stranak Z, et al. T-tube ileostomy for intestinal perforation in extremely low birth weight neonates. Pediatric

Surgery

International. 2007;23(7):685-688. DOI: 10.1007/s00383-007-1931-9.

11. Nachiappan S, Datta U, Askari A, Faiz O. Tube ileostomy for faecal diversion in elective distal colorectal anastomosis: a systematic review and pooled analysis. Colorectal Dis. 2015 ;17(8):665-73. DOI: 0.1111/codi.12997.

12. Wexner SD, Taranow DA, Johansen OB, et al. Loop ileostomy is a safe option for fecal diversion.Diseases of the Colon and Rectum. 1993;36(4):349-54.

13. García-Botello SA, García-Armengol J, GarcíaGranero E, et al. A prospective audit of the complications of loop ileostomy construction and takedown. Digestive Surgery. 2004;21(5-6):440446. DOI: $10.1159 / 000083471$.

\section{How to cite this article?}

Suryavanshi P, Rai A, suryavanshi A, Singh R. A retrospective comparative analysis of two different techniques of small bowel diversion in Ileal perforation cases: a single centre experience. Int J Med Res Rev 2016;4(12):21422146.doi:10.17511 /ijmrr. 2016.i12.11. 